\title{
Effects of High-Pressure Coolant Jets on the Machinability of Ti-6Al-4V Alloy with External Rotary Liquid Applicator
}

Nazma Sultana ( $\sim$ nazma.kuet@yahoo.com )

Bangladesh University of Engineering \& Technology

Nikhil Ranjan Dhar

Bangladesh University of Engineering \& Technology

\section{Research Article}

Keywords: Milling, Cooling, Rotary Applicator, Machinability, Ti-6Al-4V alloy, Wear.

Posted Date: January 25th, 2022

DOI: https://doi.org/10.21203/rs.3.rs-1135829/v1

License: (c) (1) This work is licensed under a Creative Commons Attribution 4.0 International License.

Read Full License 


\title{
Effects of high-pressure coolant jets on the machinability of Ti-6Al-4V alloy with external rotary liquid applicator
}

\author{
Mst. Nazma Sultana, Nikhil Ranjan Dhar \\ Department of Industrial and Production Engineering, Bangladesh University of \\ Engineering \& Technology, Dhaka-1000, Bangladesh
}

Correspondence details: Mst. Nazma Sultana; e-mail:nazma.kuet@yahoo.com

\begin{abstract}
A novel rotary applicator has been designed to feed high-pressure coolant jets while maintaining the tool's strength in order to improve the Ti-6Al-4V alloy's poor machinability. Average cutting temperature, principal cutting force, mean surface roughness, and tool wear were all taken into account when evaluating the machinability of various speed-feed combinations. Dry milling produced the worst results for all of the investigated reactions, with excessive tool wear and poor machinability happening due to the lack of cooling and lubrication. HPC and RHPC both outperformed dry, but RHPC was the clear winner in all investigations. HPC is distinguished by the rotational supply of high pressurized coolant jets delivered through several nozzles rather than the typical nozzle. This results in effective cooling and lubricating during RHPC. The higher forced convection heat transfer mechanism of high-pressure cutting fluids controls cutting temperatures amazing along with its protective film formation. Cutting forces and surface roughness are reduced roughly $14 \%$ and $17.44 \%$ in RHPC compared to HPC. Similarly, as a result of better temperature management by RHPC, flank wear is greatly reduced while tool life is increased ( 9 min).
\end{abstract}

Keywords: Milling, Cooling, Rotary Applicator, Machinability, Ti-6Al-4V alloy, Wear.

\section{Introduction}

Due to its outstanding features - high hardness at a low weight, nontoxicity, corrosion resistance, and capacity to function at elevated temperatures - the use of Ti-alloy (Grade 5) has been expanded in a variety of industrial sectors [1]. Despite these attractive properties, manufacturers and researchers have observed several complications during machining: excessive hardness at high temperatures, low thermal conductivity ( $80 \%$ less than steel), low elastic modulus (50\% less than steel), and high chemical reactivity (formation of $\mathrm{TiO} 2$ ), all of which have a detrimental effect on machinability indices, specifically surface quality, process stability, and tool life [2]. To date, dry machining has been regarded as the most sustainable method of machining in terms of minimizing negative economic, environmental, and health impacts [3]. However, dry machining is judged ineffective for mitigating temperature-related concerns. Researchers have used conventional flood cooling with low pressure to transform difficult-to-cut alloys that had been deemed ineffective due to low pressurized coolants' inability to reach efficiently into the key cutting zone of the secondary shear area (three heat generation zones related to machining are shown in Fig. 1). Additionally, environmental concerns, increased coolant costs, disposal expenses, and health risks associated with bacterial and fungal infections have intensified researchers' efforts to develop alternatives to conventional cooling [4]. The use of cutting fluids at a low rate is argued to be the superior approach due to increased productivity and improved product quality [5]. Thus, several researchers have advocated for the use of coolants with elevated pressure in machining difficult-to-cut alloys (such as Ti-alloy, Ni-based alloy) to improve cooling and lubrication [6]. Nandy et al. [7] evaluated the beneficial effects of HPC-assisted turning Ti alloy on the longevity of tool life, cutting forces, frictional behavior, and surface integrity and observed a $250 \%$ increase in tool life over wet cooling. Ezugwu et al. [8] investigated the effects of externally applied HPC on Ti-alloy turning and discovered increased tool life (less nose wear) and decreased surface roughness. 


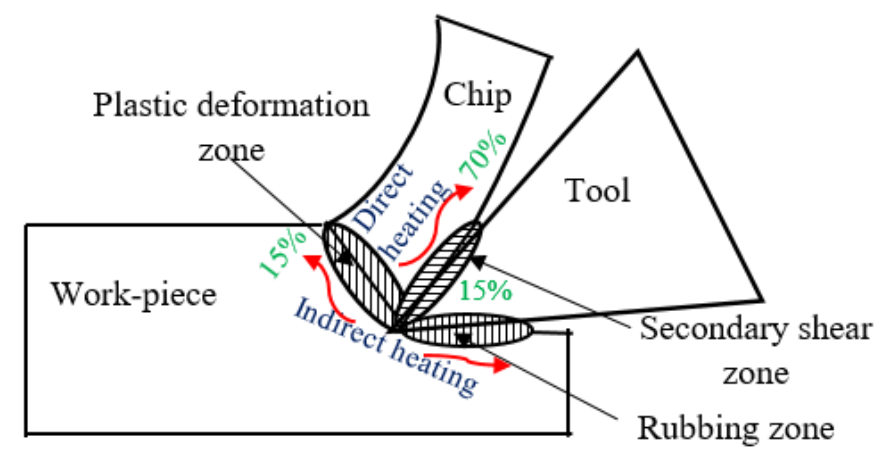

Fig. 1 Three different heat generation zone with a percentage of heat sharing by chips, tool, and workpiece.

With varied oil flow pressures and different tool materials, another study conducted by Ezugwu et al. [9] found that employing HPC with CBN tools led to an increase in tool life of $100 \%$ when compared to wet cooling. da Silva et al. [10] investigated the effects of externally applied coolant jets in all directions on Ti-6Al-4V alloy machining and found that they produced better results. By developing a specialized nozzle, Khan et al. [2] evaluated the impact of high-pressured coolant jets on the tool's surfaces during turning Ti-6Al-4V alloy. They also investigated the performance indices cutting forces, temperature, and chip formation. The authors demonstrated that high-pressure coolant jets considerably increase machinability via their cooling and wedge effects. Mia et al. [11] investigated two distinct features (roughness and wear) of Ti-6Al-4V alloy in turning under HPC employing double jets and achieved a $40 \%$ increase in tool life while maintaining acceptable surface quality. Klocke et al. [12] compared HPC to traditional cooling in milling aircraft alloy and discovered a $25 \%$ and $50 \%$ reduction in tool temperature and tool wear, respectively. Sanchez et al. [13] conducted a thorough examination of the possible benefits of HPC with a variety of coolant supply directions and noted its superiority over other cooling approaches in terms of improving machinability.

Internal cooling techniques have been examined by several scholars, and it has been argued that internal cooling can be a useful tool for machining various metals and alloys [14]. Islam et al. [15] devised and manufactured an internal cooling tube through an end mill tool to provide liquid nitrogen during milling of hardened EN 24 steel and demonstrated the influence on surface roughness, tool wear, and cutting forces. The scientists indicated that the increased machinability was a result of the cooling system's proper heat transfer mechanism, which was based on fluid dynamics. Sun et al. [16] examined the impact of internal cooling on heat generation during Al6063 machining. According to another study, an internal cooling system is more appropriate at lower speeds and feed rates, as determined by the examination of certain efficiency ratios [17]. Peng et al. [18] developed a unique grinding wheel with an internal cooling channel for machining nickel-based superalloys and observed that it outperformed flood cooling in terms of heat transfer performance. Oezkaya et al. [19] investigated internal cooling in drilling and discovered that coolant jets applied at the appropriate pressure through the internal channel considerably reduced tool wear. Zhang et al. [20] investigated the performance of milling H13 steel using milling cutters equipped with internal cooling channels at each tooth to supply cooled compressed air with a trace amount of lubricant in terms of cutting force, tool wear, and environmental concerns. However, an internal cooling channel running through the tool diminishes the tool's rigidity against hard materials when the feed rate is increased [21]. Due to the hollow part running through the tool, the rate of a catastrophic failure or breakage increases during high-speed cutting, resulting in decreased tool life. Additionally, in the majority of cases, those channels are created by an expensive and time-consuming electro-discharge machining method. However, impinging cutting fluids properly through the use of a standard external nozzle is not easy, as the flow of coolant jets is halted by the revolving cutter's centrifugal force. In this case, external application of cutting fluids by any rotary applicator is likely to aid in overcoming these impediments.

Analyzing previous research, it is clear that while the study of HPC in turning Ti-6Al-4V alloy has reached a zenith with a remarkable increase in machinability, further focus is required to address its effects on the intermittent milling process in detail, allowing for the expansion of Ti- alloy's in producing different shapes and complex parts. However, the majority of those experiments used a conventional single-jet nozzle or an internal cooling mechanism with the goal of fast removing heat, but the challenges associated with both conventional cooling and internal cooling are not adequately addressed. Due to this gap in the knowledge base about milling Ti-6Al-4V alloy, the authors were inspired to seek a better solution than the typical cooling procedures used in milling. The authors developed a specialized rotary applicator without compromising the rigidity of the tool and examined 
the effects of HPC on cutting temperature, main cutting force, surface roughness, and tool wear while milling Ti-6Al-4V alloy using the designed applicator. They also conducted a comparative analysis of dry, conventional HPC, and RHPC milling.

\section{Materials and Methods}

The bimodal microstructured ( $\alpha+\beta$ phased) Ti-6Al-4V alloy (Grade 5, hardness 37HRC) was chosen as the workpiece material in this investigation due to its reduced density and superior strength-to-weight ratio when compared to conventional steels and aluminum. Tables $\mathbf{1}$ and $\mathbf{2}$ detail the chemical composition and mechanical attributes of the Ti-6Al-4V alloy used in this investigation.

Table 1. Chemical composition of Ti-6Al-4V alloy (Grade 5)

\begin{tabular}{lccccccc}
\hline Chemical elements & $\mathrm{Al}$ & $\mathrm{V}$ & $\mathrm{Fe}$ & $\mathrm{O}$ & $\mathrm{N}$ & $\mathrm{C}$ & $\mathrm{Ti}$ \\
\hline$\%$ wt. & 6.43 & 4.12 & 0.049 & 0.16 & 0.012 & 0.011 & Balance \\
\hline
\end{tabular}

Table 2. Mechanical properties of Ti-6Al-4V alloy (Grade 5)

\begin{tabular}{llllllll}
\hline $\begin{array}{l}\text { Melting } \\
\text { point }\end{array}$ & $\begin{array}{l}\text { Specific } \\
\text { density }\end{array}$ & $\begin{array}{l}\text { Thermal } \\
\text { conductivity }\end{array}$ & $\begin{array}{l}\text { Specific } \\
\text { heat }\end{array}$ & $\begin{array}{l}\text { Ultimate } \\
\text { tensile } \\
\text { strength }\end{array}$ & Elongation & $\begin{array}{l}\text { Tensile } \\
\text { strength }\end{array}$ & Hardness \\
\hline $1604^{\circ} \mathrm{C}$ & $\begin{array}{l}4.43 \\
\mathrm{~g} / \mathrm{cm}^{3}\end{array}$ & $6.7 \mathrm{~W} / \mathrm{m}-\mathrm{k}$ & $\begin{array}{l}0.5263 \\
\mathrm{~J} / \mathrm{g}^{0} \mathrm{C}\end{array}$ & $\begin{array}{l}1000 \\
\mathrm{MPa}\end{array}$ & $14 \%$ & $550 \mathrm{MPa}$ & $37 \mathrm{HRC}$ \\
& & & & & & \\
\hline
\end{tabular}

Milling experiments were conducted on a vertical knee and column milling machine (7.5hp, Sunlike, China). High-speed steel (HSS) with a hardness of $65 \mathrm{HRC}$, an outer diameter of $12 \mathrm{~mm}$, a helix angle of $30^{\circ}$, four flutes with center cutting and a rake angle of $0^{\circ}$, a length of cut of $27 \mathrm{~mm}$, and an overall length of $83 \mathrm{~mm}$ was chosen as the tool material. Machining at low cutting velocities motivates us to prefer a highly economical HSS tool over a carbide tool because the ductility of HSS allows it to maintain its cutting stability against milling forces at lower cutting velocities without premature breakage, which is also consistent with previous research [15].

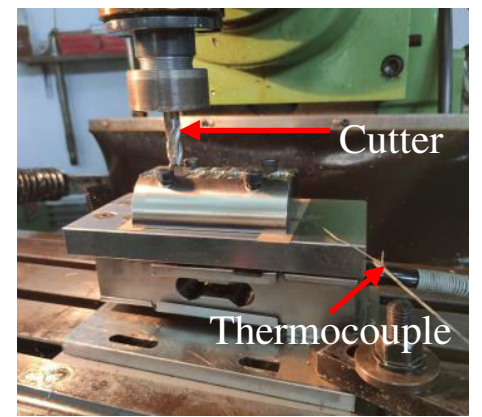

(a)

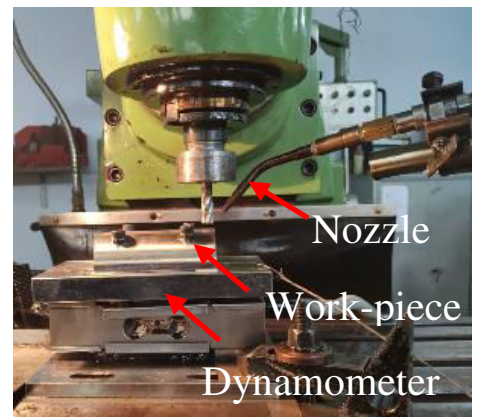

(b)

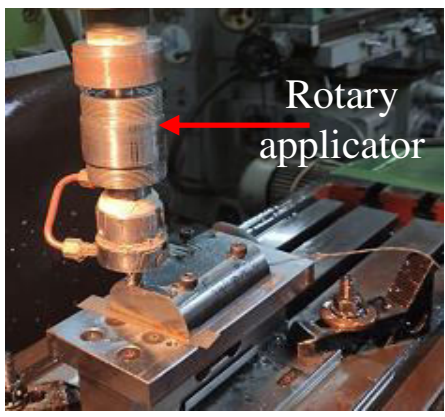

(c)

Fig. 2 Milling of Ti-6Al-4V alloy under (a) dry; (b) conventional HPC and (c) RHPC.

As seen in Fig. 2, milling was performed under three distinct cutting conditions: dry (DM), standard high-pressure cooling (HPC), and high-pressure cooling using an external rotating liquid applicator (RHPC). Dry milling tests were conducted without the use of any cutting fluids. As previously stated, traditional flood cooling is unsuitable for machining such poor thermal conductivity Ti-6Al-4V alloys. According to their recommendations, the use of high-pressured coolant jets may be an effective option. On this basis, we built the HPC setup depicted schematically in Fig. 3 in our manufacturing lab. It is divided into two major components: one is responsible for creating high pressure, while the other is responsible for supplying high pressurized coolant jets into the cutting zone. To provide an uninterrupted supply of cutting fluids, the flow rate was set to $2 \mathrm{~L} / \mathrm{min}$ with an oil pressure of $80 \mathrm{bar}$, and the nozzle position was set to $25 \mathrm{~mm}$ after trial and error.

Proper cutting fluid penetration at the secondary shear zone is a difficult challenge in intermittent milling due to the complex tool geometry and critical chip creation. Additionally, in end milling, heat is generated on both sides (side and end faces) of the tool to a predetermined depth (defined by the axial depth of cut). Keeping this in mind, the high-pressured coolant jets were supplied via an external rotating liquid applicator that was mounted on a spindle and also served to tightly hold the end mill 
tool. The developed rotary liquid applicator's key components include an adapter, an oil chamber, heatproof bearings and Teflon seals, a particularly designed jam nut, a tiny oil chamber with embedded nozzles $(0.50 \mathrm{~mm})$, and a connector.

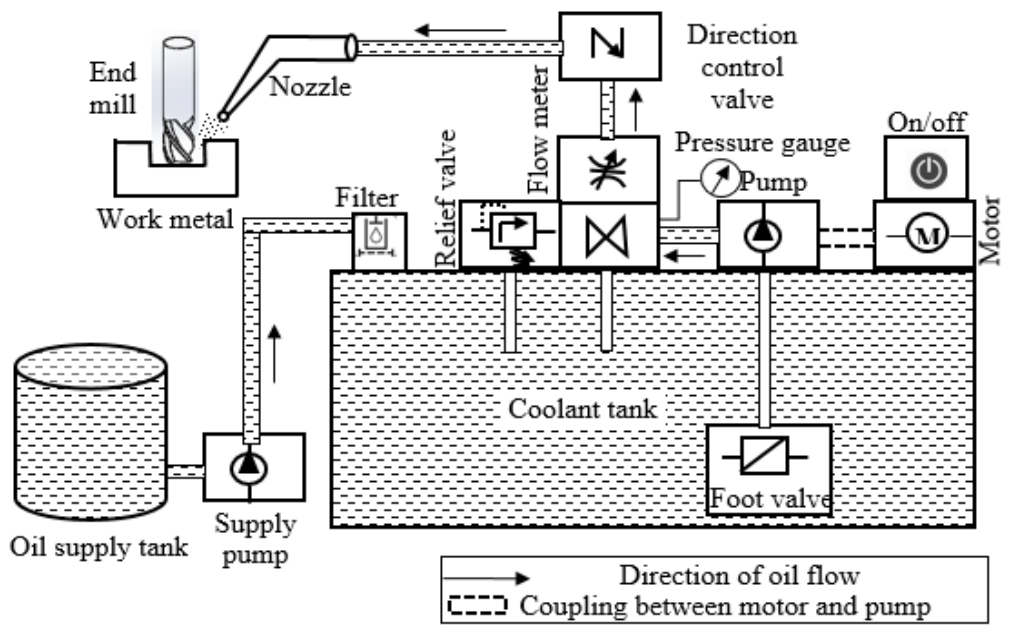

Fig. 3 Schematic diagram of HPC set up with conventional external nozzle.

The adapter was designed to securely hold the other components and was also coupled with a spindle via a collet and jam nut. The high-pressure coolant jets were provided from the flexible hose to the oil chamber via a small hole $(4.0 \mathrm{~mm})$ and were enabled to flow from the oil chamber to the adapter and finally to the mini oil chamber via a channel, as seen in Fig.4. Following that, coolant jets were shot from four angularly implanted nozzles placed along the flute length and rotated. Fig.4 illustrates the sectional and isometric views of the designed external rotating liquid applicator, as well as its measurements. Both HPC and RHPC milling was performed with VG-68 straight cutting oil as the high-pressure cutting fluid. The experimental investigations were designed to be carried out at a variable cutting velocity $(16 \sim 32 \mathrm{~m} / \mathrm{min})$ and table feed rate $(22 \sim 68 \mathrm{~mm} / \mathrm{min})$ under a variety of cutting conditions and a constant depth of cut of $1.0 \mathrm{~mm}$, to determine the machinability of Ti-6Al-4V alloy in terms of cutting temperature, cutting force, surface roughness, and tool wear. Table 3 summarizes the experimental settings under which milling tests were conducted.

Table 3. Experimental conditions.

\begin{tabular}{|c|c|}
\hline Machine Tool & Vertical knee and column type milling machine (Sunlike, china) \\
\hline \multirow[t]{2}{*}{ Work materials } & Convex shaped Ti-6Al-4V alloy (Grade 5) \\
\hline & Dimension: $100 \times 50 \times 25$ \\
\hline Tool type & High-speed steel (HSS $\varnothing 12 \mathrm{~mm}$ ) End mill cutter \\
\hline \multicolumn{2}{|l|}{ Process parameters } \\
\hline Cutting velocity, $\mathrm{m} / \mathrm{min}$ & $16,24,32$ \\
\hline Table feed, $\mathrm{mm} / \mathrm{min}$ & $22,44,68$ \\
\hline Depth of cut, mm & 1.0 \\
\hline Cutting fluid type & VG-68 cutting oil \\
\hline Cutting conditions (CC) & Dry, HPC and RHPC \\
\hline \multicolumn{2}{|l|}{ RHPC parameters } \\
\hline Oil flow rate, $\mathrm{L} / \mathrm{min}$ & 2 \\
\hline Oil pressure, bar & 80 \\
\hline Nozzle angle & $35^{0}$ \\
\hline Nozzle dia. mm & 0.5 \\
\hline No. of nozzles & 4 \\
\hline $\begin{array}{l}\text { Nozzle Distance from } \\
\text { the stagnant point, } \mathrm{mm}\end{array}$ & 20 \\
\hline Responses & $\mathrm{T}, \mathrm{F}_{\mathrm{c}}, \mathrm{R}_{\mathrm{a}}, \mathrm{V}_{\mathrm{b}}$ \\
\hline
\end{tabular}




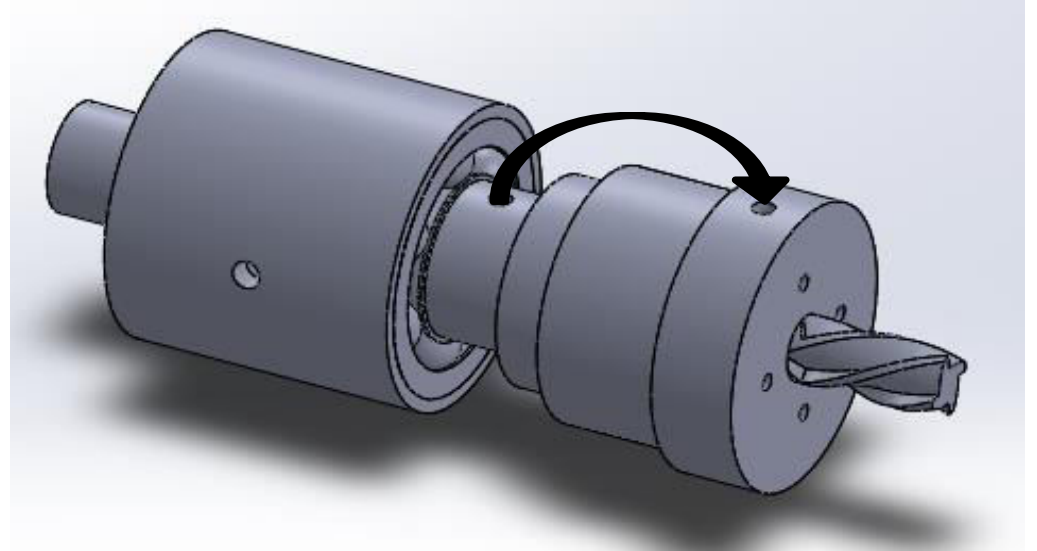

(a)

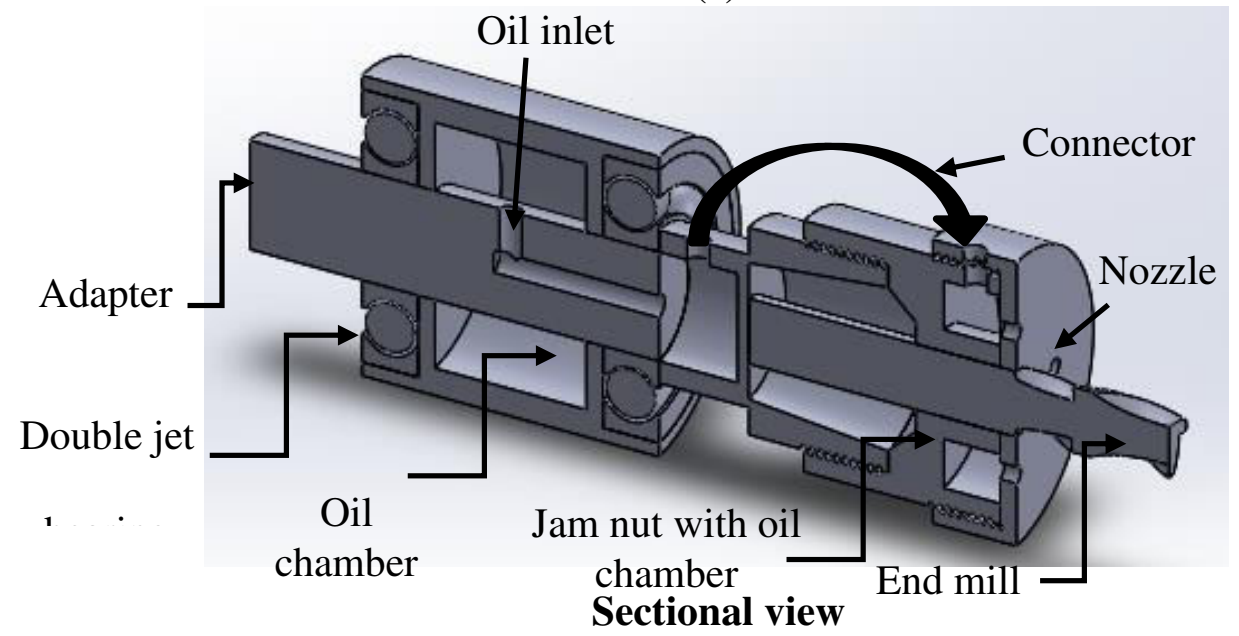

(b)

Fig. 4 (a) Isometric view and (b) sectional view of the designed rotary liquid applicator.

The full factorial-based design of experiment (DoE) was used to organize the experimental trial runs systematically since it calculates all potential combinations of selected input variables with the least amount of error [22]. Cutting temperatures (T) were determined using the tool-work thermocouple method under all cutting conditions, utilizing Ti-6Al-4V alloy and HSS end mill cutters as dissimilar metals. This approach is straightforward but accurate for monitoring cutting temperature across the full contact region across a large temperature range. The schematic representation of the specific tool-work thermocouple loop is given in Fig. 5. Calibration is required to define the relationship between voltage generation and real temperature for the tool-work combination being employed. To facilitate calibration, a long length of chip and a segment of the HSS tool were brazed together at one end, rather than the actual work material and end mill cutter. A graphite block was placed on the porcelain of an electrically powered radiant heater to act as a heat sink. In the graphite block, the brazed junctions of the tool-work thermocouple and the standard thermocouple (K-TYPE) were arranged adjacent to one another. The chip and HSS tool segment's other ends were connected via the digital multimeter (Rish multi 15S, India). The porcelain and graphite blocks were then electrically heated, and the brazed connection acted as the thermocouple's hot junction. The multimeter was used to record the thermoelectric voltage created, as well as the direct temperature $\left({ }^{\circ} \mathrm{C}\right)$ of the heated graphite block using a digital thermometer (Eurotherm, UK). Finally, the calibration curve is shown with the observed voltage and temperature. 


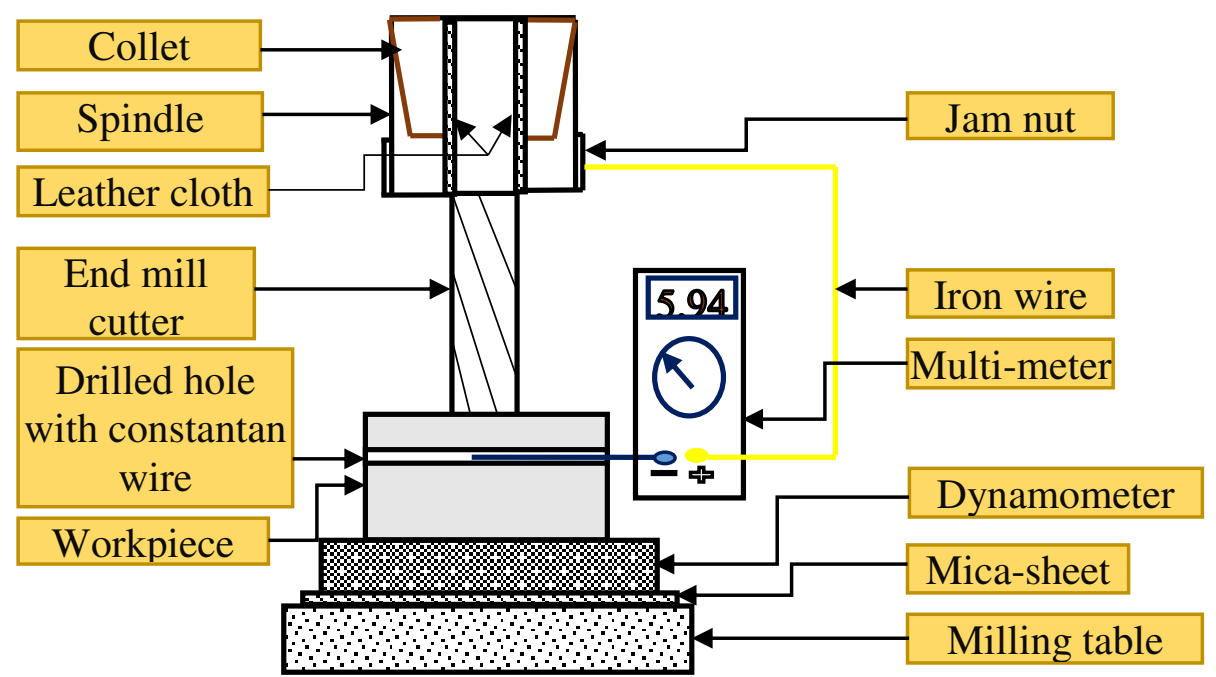

Fig. 5 Schematic diagram of specific tool-work thermocouple set up.

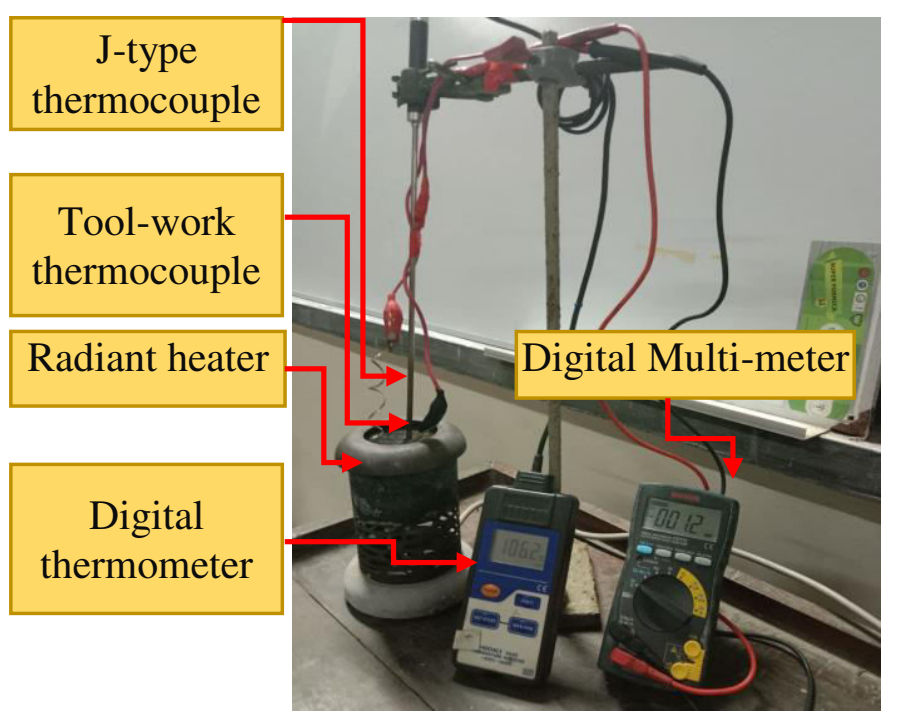

(a)

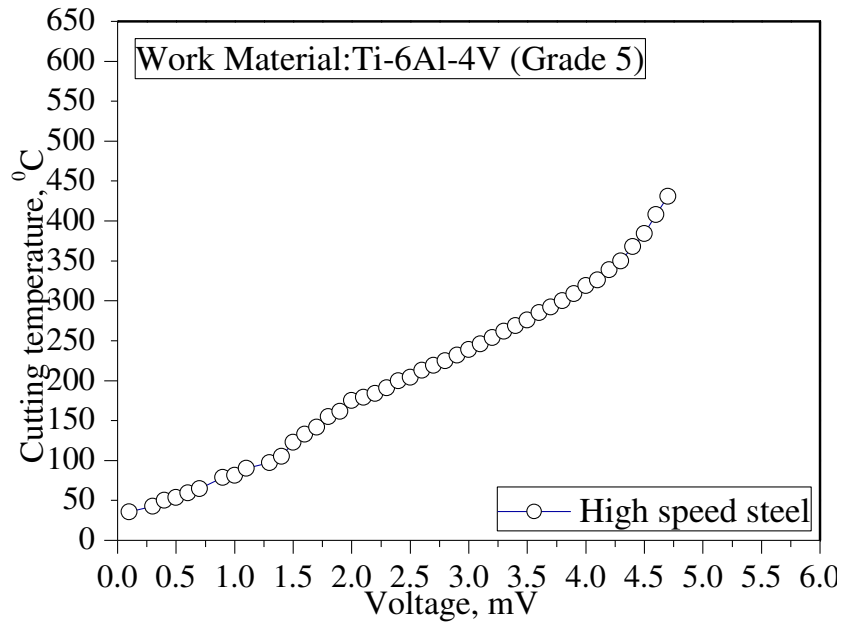

(b)

Fig. 6 Tool-work thermocouple calibration (a) set up and (b) curve. 
Figs. 6(a) and 6(b) depict the photographic perspective of the setup for tool-work thermocouple calibration. A nearly linear relationship between temperature and voltage has been established with a coefficient of determination of 98.74 percent. The regression equation used to calculate the temperature of the chip-tool interface from the thermocouple voltage is presented below:

$$
\text { Temperature }\left({ }^{0} \mathrm{C}\right)=6.59+80.13 \text { voltage }(\mathrm{mV})
$$

Cutting forces were determined during milling using a KISTLER dynamometer equipped with a load cell and charge amplifier. Surface roughness was determined for each slot using a portable Talysurf roughness checker (Surtronic 3+, Rank Hobbs, UK), with a sampling length of $0.80 \mathrm{~mm}$. Table 4 summarizes the findings from each experiment (a total of 27 runs). The rise of flank wear with machining time at constant speed-feed-depth of cut was monitored using a metallurgical microscope (Carl Zeiss, Germany) equipped with a micrometer with a resolution of $1 \mathrm{~m}$ for the purpose of determining tool life under three separate cutting scenarios.

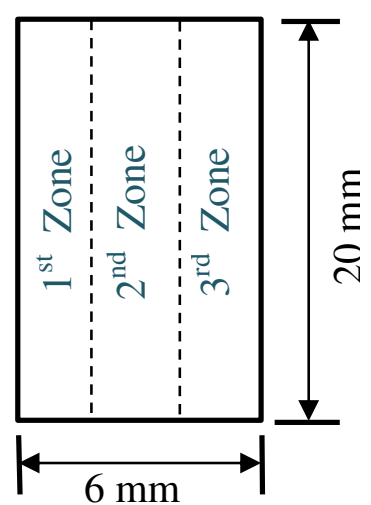

Fig. 7 Roughness measurement zones within a single slot.

Table 4. Full factorial based orthogonal array (L27) with corresponding responses.

\begin{tabular}{|c|c|c|c|c|c|c|c|}
\hline $\begin{array}{l}\text { Run } \\
\text { order }\end{array}$ & $\begin{array}{l}\text { Std. } \\
\text { order }\end{array}$ & $\begin{array}{l}\text { Speed, } \\
\mathrm{m} / \mathrm{min}\end{array}$ & $\begin{array}{c}\text { Feed, } \\
\mathrm{mm} / \mathrm{min}\end{array}$ & $\mathrm{CC}$ & $\mathrm{T}\left({ }^{\circ} \mathrm{C}\right)$ & $\mathrm{F}_{\mathrm{c}}(\mathrm{N})$ & $\mathrm{R}_{\mathrm{a}}(\mu \mathrm{m})$ \\
\hline 1 & 15 & 24 & 44 & RHPC & 472.95 & 210.19 & 1.22 \\
\hline 2 & 4 & 16 & 44 & Dry & 539.45 & 298.92 & 1.63 \\
\hline 3 & 13 & 24 & 44 & Dry & 628.40 & 269.45 & 1.55 \\
\hline 4 & 27 & 32 & 68 & RHPC & 569.10 & 207.86 & 1.08 \\
\hline 5 & 22 & 32 & 44 & Dry & 646.03 & 227.10 & 1.32 \\
\hline 6 & 1 & 16 & 22 & Dry & 348.75 & 257.80 & 1.53 \\
\hline 7 & 8 & 16 & 68 & $\mathrm{HPC}$ & 593.14 & 292.72 & 1.72 \\
\hline 8 & 21 & 32 & 22 & RHPC & 395.22 & 168.49 & 0.82 \\
\hline 9 & 2 & 16 & 22 & HPC & 327.91 & 227.93 & 1.38 \\
\hline 10 & 12 & 24 & 22 & RHPC & 351.15 & 183.27 & 0.96 \\
\hline 11 & 20 & 32 & 22 & HPC & 428.07 & 179.52 & 1.18 \\
\hline 12 & 17 & 24 & 68 & HPC & 609.97 & 254.08 & 1.59 \\
\hline 13 & 3 & 16 & 22 & RHPC & 318.30 & 196.58 & 1.24 \\
\hline 14 & 6 & 16 & 44 & RHPC & 417.66 & 227.59 & 1.30 \\
\hline 15 & 24 & 32 & 44 & RHPC & 488.17 & 179.11 & 1.00 \\
\hline 16 & 26 & 32 & 68 & HPC & 638.82 & 232.50 & 1.32 \\
\hline 17 & 7 & 16 & 68 & Dry & 624.39 & 328.05 & 2.35 \\
\hline 18 & 10 & 24 & 22 & Dry & 377.59 & 232.50 & 1.47 \\
\hline 19 & 14 & 24 & 44 & HPC & 518.62 & 237.59 & 1.32 \\
\hline 20 & 9 & 16 & 68 & RHPC & 533.04 & 259.55 & 1.42 \\
\hline 21 & 19 & 32 & 22 & Dry & 473.75 & 203.65 & 1.32 \\
\hline 22 & 18 & 24 & 68 & RHPC & 557.88 & 227.80 & 1.32 \\
\hline 23 & 16 & 24 & 68 & Dry & 630.00 & 283.08 & 2.25 \\
\hline 24 & 23 & 32 & 44 & HPC & 565.10 & 198.20 & 1.24 \\
\hline 25 & 5 & 16 & 44 & HPC & 480.16 & 267.54 & 1.44 \\
\hline 26 & 25 & 32 & 68 & Dry & 694.91 & 267.06 & 1.61 \\
\hline 27 & 11 & 24 & 22 & $\mathrm{HPC}$ & 354.77 & 198.09 & 1.34 \\
\hline
\end{tabular}




\section{Results and Discussions}

Because the ultimate objective of this research is to compare the effects of RHPC assisted milling to dry and conventional HPC assisted milling at a variety of cutting velocities and feeds, an investigation was conducted to determine the machining performance parameters such as average cutting temperature, main cutting force, mean surface roughness, and growth rate of tool wear under three different cutting conditions when milling Ti-6Al-4V alloy using an HSS end mill cutter. To begin, the cooling mechanism of the developed external rotary applicator is reviewed, followed by a brief explanation of its consequences on the indicated machining performances.

\subsection{Cooling mechanism of the external rotary liquid applicator}

For this study, the tool-chip interface (friction at rake face) and the tool-work interface (rubbing at flank face) are considered to be major heat zones for cooling, whereas the primary shear zone is considered to be negligible, following the temperature model proposed by Cui and colleagues [23]. Under all machining settings, the heat generated at the cutting zones is dispersed by following the three common routes of heat transformation: conduction (medium: tool, chip, and workpiece), convection (medium: air and cutting fluids), and radiation (higher energy: tool, chip, and workpiece) (medium: air). The following is a quantitative description of the distribution of generated heat at the cutting zone:

$$
q_{\text {total }}=q_{w}+q_{t}+q_{c}+q_{l}
$$

Where, $q_{\text {total }}$ is the total quantity of heat generated during cutting; $q_{w}$ is the quantity of heat absorbed by the workpiece; $q_{t}$ is the quantity of heat conducted by the tool; $q_{c}$ is the quantity of heat carried away by chips; $q_{l}$ is the quantity of heat loss due to radiation. Due to the lack of cutting fluids in dry machining, the convective heat transformation rate is zero, resulting in the majority of the heat being trapped at the cutting zone for an extended period, which reduces machinability and increases machining time. In conventional HPC, the external nozzle is kept static and in a fixed position, allowing for precise impingement of high-pressure cutting fluids (up to $80 \mathrm{bar}$ ), which increases the forced convective heat transformation. However, it is expected that transforming nonrotational fluids into rotational fluids can greatly improve the cooling effectiveness of such typical HPCs since such type rotating fluids carry out more heat than nonrotational fluids by reducing the hydraulic loss significantly [24]. To take advantage of this feature in our design, the modified jam nut with a tiny oil chamber is designed to rotate by the spindle through an adapter at the same rotational speed as the cutter. When fluid enters the rotational oil chamber from the static oil chamber through an adapter, tangential forces act between the rotational chamber and the fluid, changing the flow pattern of fluids, and centrifugal forces are formed radially. Swirl flow is created as a result of the development of centrifugal forces, which adds to the increase in heat transfer capacity [15]. In respect of using numerous embedded jets the likelihood of mutual disruptions among the adjacent jets after impingement on the target point is a common problem [6]. To avoid such issues, four nozzle jets are arranged in a $360^{\circ}$ circular arrangement with the angular distance between each nearest jet remaining at $90^{\circ}$. As a result, the revolving jets are sprayed onto the four flutes of the tool from four separate directions at the same time. Additionally, the use of small diameter inlets accelerates jet impingement with high pressure, which in turn increases heat transfer through the formation of an ultra-thin boundary layer in the cutter's stagnation regions. [25, 26] According to experts, the heat transfer is greatest at the stagnation point, and in this design, the stagnation point was made at the very nearest zone of tooltip for each tooth. That also increases the average Nusselt number. The Nusselt number $(\mathrm{Nu})$ is a unitless number used in the analysis of heat transfer in fluids. It is essentially the ratio of convective to conductive heat transfer at a fluid boundary. Heat convection is higher for larger Nusselt numbers for the turbulent flow (range: 100-1000), while lower Nusselt numbers indicate less active convection. It can be stated mathematically as follows:

$$
N u=\frac{\text { convective heat transfer }\left(q_{c}\right)}{\text { conductive heat transfer }\left(q_{c o}\right)}=\frac{h D}{k}
$$

$\mathrm{D}$ is the nozzle's diameter and $\mathrm{k}$ is the fluid's thermal conductivity. $\mathrm{h}$ symbolizes the convective heat transfer coefficient. During turbulent flow, the peak of the Reynolds number will be located at the place where the Nusselt number is highest since these two dimensionless numbers are connected [25]. 
Finally, it can be claimed that by increasing the forced convective heat transfer rate, a beneficial synergistic effect of rotational multiple jets can efficiently regulate the increased cutting temperature. Another positive effect was observed that HPC coolant jets remove the chips by correctly penetration on the cutting area, which is also supported by the other findings of previous research related to highpressure coolant jets [10].

\subsection{Effects on Cutting temperature $(T)$}

Cutting temperature is a critical factor in determining machinability. Despite its beneficial impacts on machining, it is the primary cause of inefficient machining processes [27]. High cutting temperatures have a noticeable effect on tool life, power consumption, and surface finish. Controlling the cutting temperature is critical due to its most detrimental consequences. The variation in cutting temperature as a function of cutting velocity and table feed under various cutting conditions is depicted in Fig.8. The trend in altering cutting temperature is positive as cutting velocity and feed are increased, indicating that cutting temperatures increase in all cutting situations, which is consistent with prior research findings [28]. According to the graphical plot, the cutting temperature shift is greatest for cutting velocity, followed by cutting condition, and finally by table feed rate, which is consistent with the findings of another researcher [29].

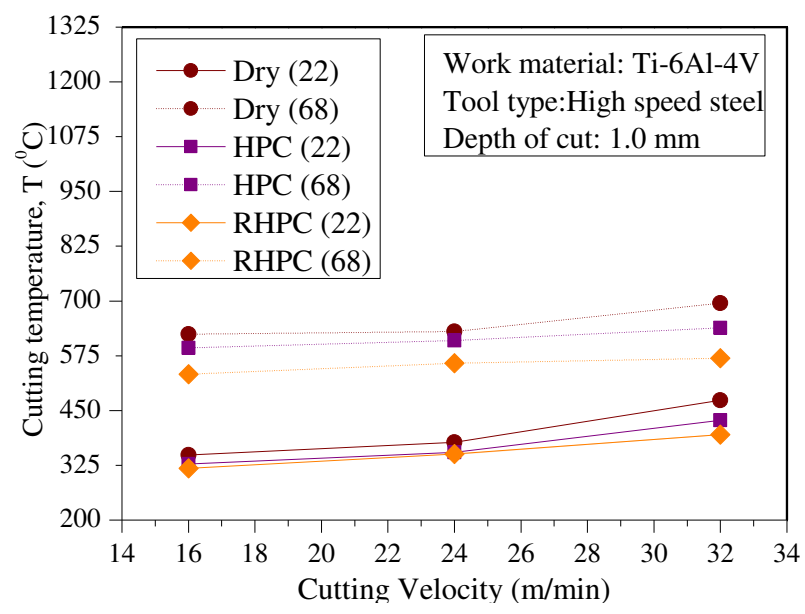

Fig. 8 Variation of cutting temperature with cutting velocitys in milling Ti-6Al-4V alloy at different table feed ( 22 and $68 \mathrm{~mm} / \mathrm{min}$ ) with $1.0 \mathrm{~mm}$ depth of cut under three different cutting conditions.

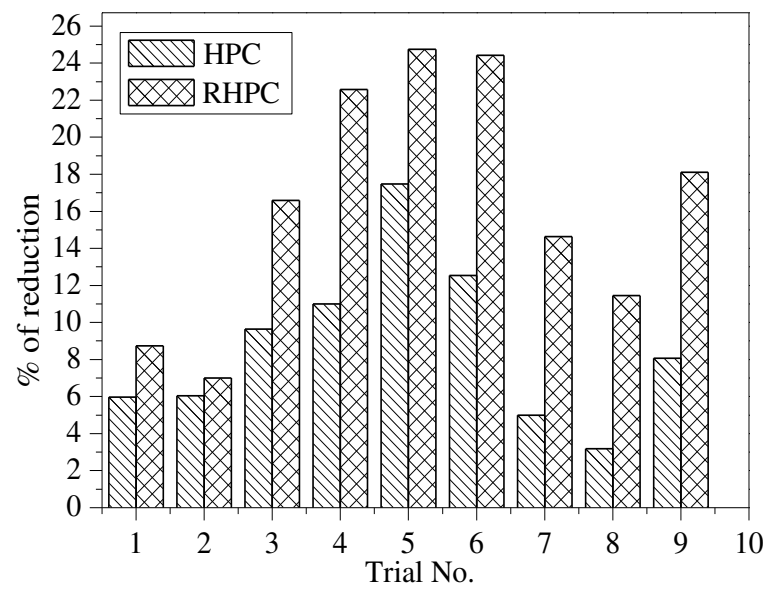

Fig. 9 Percentage reduction of cutting temperature under HPC and RHPC over dry milling of Ti6Al-4V based on experimental runs. 
Fast chip formation combined with severe tool wear at high cutting velocity leads to an increase in the cutting temperature at the secondary shear zone. Similarly, the increased cutting temperature associated with high feed rates is attributable to the increased tool-chip contact zone, which results in increased friction and rubbing [30]. These catastrophic effects are successfully mitigated in this research work by utilizing high-pressure cooling (HPC). The higher thermal conductivity of the cutting fluid used enables the removal of more heat via convection rather than conduction into the surfaces of a tool and work material, as observed in another research work on continuous machining of Ti-6Al-4V alloy [7]. This cooling rate of high-pressured coolant jets is contingent upon their successful entry into the cutting zone via chip removal via the wedge effect at the route of penetration. As illustrated in Fig. 9, RHPC offers superior cooling to standard HPC. HPC results in a temperature decrease of 3 19.84 percent, while RHPC results in a temperature reduction of 7 26.71 percent. In RHPC, the increased penetration of high-pressure coolant jets along the flute length effectively lubricates the tool-work interfaces due to its increased penetrability and wettability. Additionally, it decreases friction area, which enables rapid heat dissipation. The average temperature for dry milling was determined to be roughly $700^{\circ} \mathrm{C}$, which was decreased to $638^{\circ} \mathrm{C} \mathrm{HPC}$, which is closer to the earlier study results given by [31] for end milling with minimal lubrication. However, in RHPC, this cutting temperature was observed to be $569^{\circ} \mathrm{C}$, implying that RHPC has a better cooling efficiency than standard HPC.

\subsection{Effects on Main cutting force $\left(F_{c}\right)$}

Cutting force (the force required to remove excess metal as chips via shear) is a representative index of process stability (power and energy, tool vibration, and chattering) that is strongly influenced by toolwork material, process variables $\left(\mathrm{V}_{\mathrm{c}}, \mathrm{f}, \mathrm{a}_{\mathrm{p}}\right)$, coolant types and application methods [28]. The variation in cutting force $\left(\mathrm{F}_{\mathrm{c}}\right)$ as a function of process factors under various cutting conditions is depicted graphically in Fig. 10.

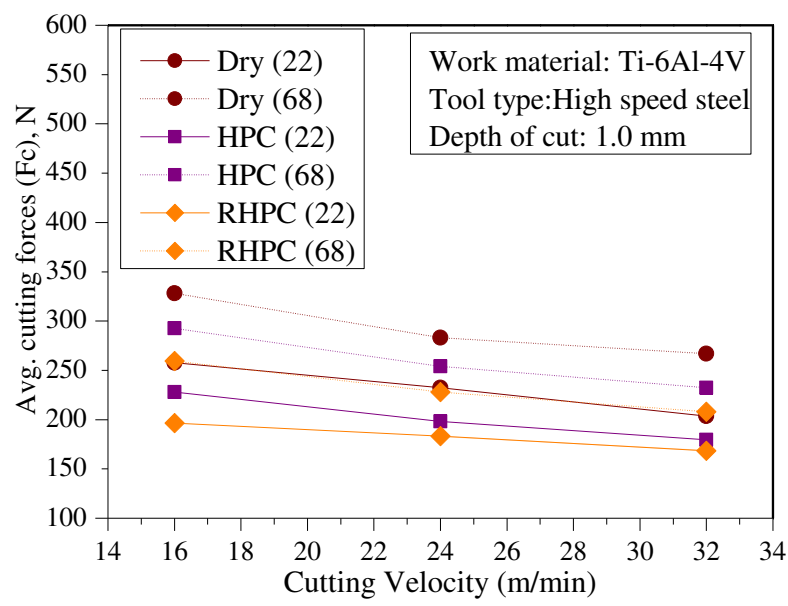

Fig. 10Variation of average cutting forces with cutting velocitys in milling Ti-6Al-4V alloy at different table feed ( 22 and $68 \mathrm{~mm} / \mathrm{min}$ ) with $1.0 \mathrm{~mm}$ depth of cut under three different cutting conditions.

As can be observed, cutting force decreases as cutting velocity increases, whereas feed rate increases in all cutting circumstances. The decrease in cutting force as cutting velocity increases is attributed to thermal softening before plastic deformation, whereas the increase in cutting force at a higher feed rate is attributed to strain hardening predominating over thermal softening with increased chip load, which is consistent with previous research results [6, 32]. The main cutting force, on the other hand, rises with increased table feed due to increased friction and chattering associated with rapid tool wear development. Apart from cutting velocity and feed, cooling has a considerable effect on cutting force reduction. The maximum cutting force $(328.05 \mathrm{~N})$ was discovered during dry milling, which is the result of high heat formation combined with rapid plastic deformation, which suppresses thermal softening via strain hardening, which is more consistent with earlier studies [6]. Additionally, high heat accelerates tool wear progression significantly, which increases the tool's rubbing and friction behavior, as well as process instability during dry milling, which can also be noted for the enhancement of cutting force. By their wedge effect and lubricity, high-pressure coolant jets reduce cutting effort by reducing the seizure area and friction coefficients. Additionally, the increased tool life 
achieved through the use of high-pressure coolant jets has a beneficial influence on cutting force reduction.

Regardless of process conditions, Fig. 11 demonstrates that RHPC significantly reduces cutting force (percent reduction is 17 24 percent greater than dry) than traditional HPC (percent reduction is 10 14 percent greater than dry). This occurrence is explicable by the adequate lubrication of RHPC. Cutting fluids are blasted through four nozzles at high pressure in RHPC, ensuring a greater distribution of cutting fluids at each cutting edge (four teeth) than is possible with a standard stationary supply via a single nozzle. This rotating distribution is said to preserve the sharpness of each cutting edge while minimizing BUE and chipping, which is impossible with standard HPC. As a result, the force required for cutting is lowered further without sacrificing any single cutting edge catastrophically. Additionally, the many jets with the same oil flow rate effectively reach the cutting zone, ensuring that it outperforms conventional HPC in terms of effectiveness.

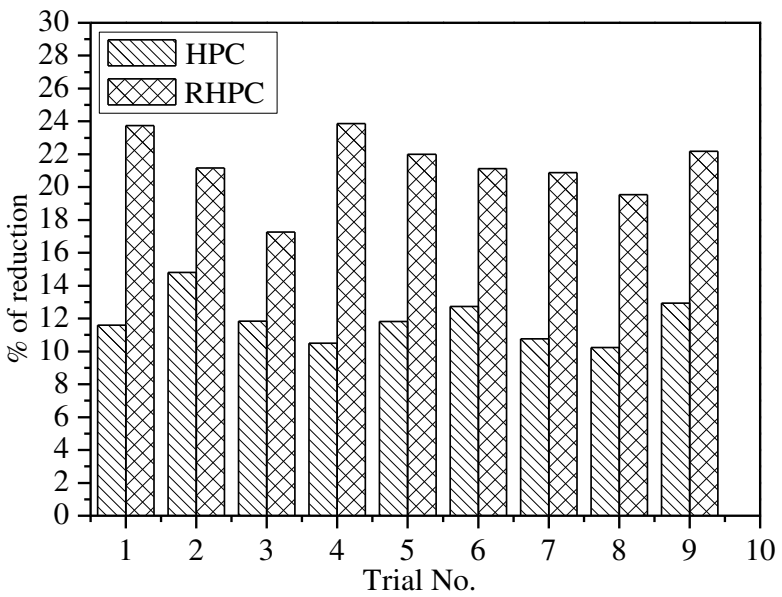

Fig. 11 Percentage reduction of average cutting forces under HPC and RHPC over dry milling of Ti-6Al$4 \mathrm{~V}$ based on experimental runs.

\subsection{Effect on Surface roughness $\left(R_{a}\right)$}

Surface roughness is another important measure of machinability, being greater under unstable machining settings with a greater cutting force than under stable machining conditions [33]. Surface roughness is critical in boosting the machined part's quality and service life. Grinding is generally used to get the ultimate finish on any turned or milled product. Although grinding is necessary for highly completed items, it will save time and money if it can make pieces close to their final shape with the least amount of roughness. Frequent feed marks, built-up edges, unstable machining conditions with increased vibration and chattering, a weak machine-fixtures-tool-work system, increased tool wear, increased work material hardness, and improper machining condition selection is considered to be the primary causes of increased surface roughness [11]. Fig. 12 illustrates the changing behavior of average surface roughness $\left(\mathrm{R}_{\mathrm{a}}\right)$ as a function of cutting velocity and feed under three different cutting settings.

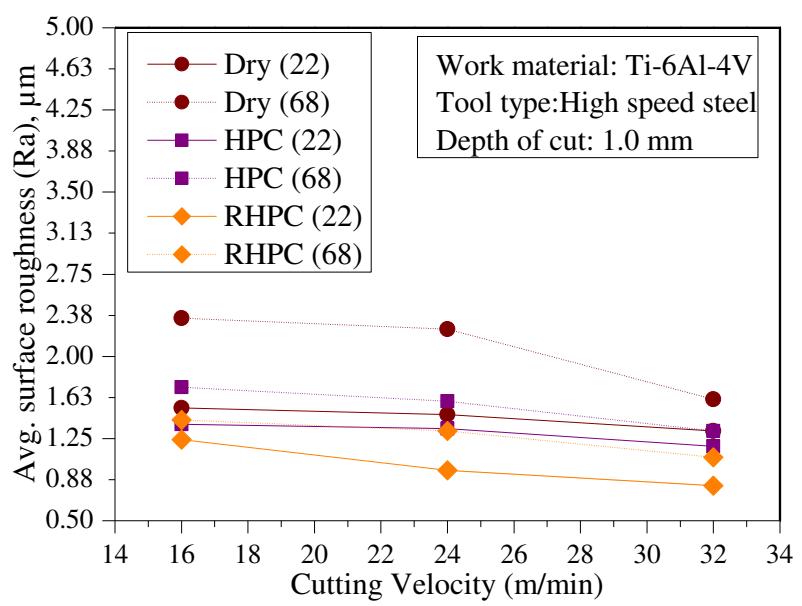

Fig. 12 Variation of average surface roughness with cutting velocitys in milling Ti-6Al-4V alloy 
at different table feed (22 and $68 \mathrm{~mm} / \mathrm{min}$ ) with $1.0 \mathrm{~mm}$ depth of cut under three different cutting conditions.

The graphical representation demonstrates that the average surface roughness gradually reduces as the cutting velocity increases. This can be related to the work material's local thermal softening (a less thermally conductive Ti-6Al-4V alloy confines heat for an extended period) at a specific temperature, as shown in another research finding [34]. Additionally, less BUE generation with a smaller contact area and less chattering at a faster cutting velocity [11] decrease surface roughness. However, under all cutting settings, the changing trend is reciprocal with the feed rate, which is consistent with the established theoretical relationship $\left(R_{a} \infty \frac{f^{2}}{r}\right)$ between roughness $\left(\mathrm{R}_{\mathrm{a}}\right)$ and feed rate (f) [35]. Additionally, this can be explained mechanically, as a faster feed rate results in frequent feed markings and increased vibration as a result of the increased chip load [4]. The effect of cutting circumstances on the average roughness of the surface is also noteworthy. In dry milling, greater surface roughness was discovered, which is the result of increased rubbing between tool and chip, as well as increased friction between tool and work due to frequent chattering. While increased cutting velocity improves surface roughness, dry milling of Ti-6Al-4V alloy metal flows due to plastic deformation at high temperatures create an imbalanced hardness. Additionally, the superalloy's higher chemical affinity facilitates the adhesion of foreign metals to its surface, resulting in increased roughness [15]. Increased surface roughness is also caused by the faster evolution of tool wear in the absence of coolant/lubricant [36]. High-pressure coolant jets reduce friction between interfaces [36], prevent burr formation by breaking chips, and reduce chemical bonding of foreign materials on the job surface by washing away chips [38], all of which result in reduced surface roughness for both types of HPC, though the rate of reduction is greater for rotary HPC.

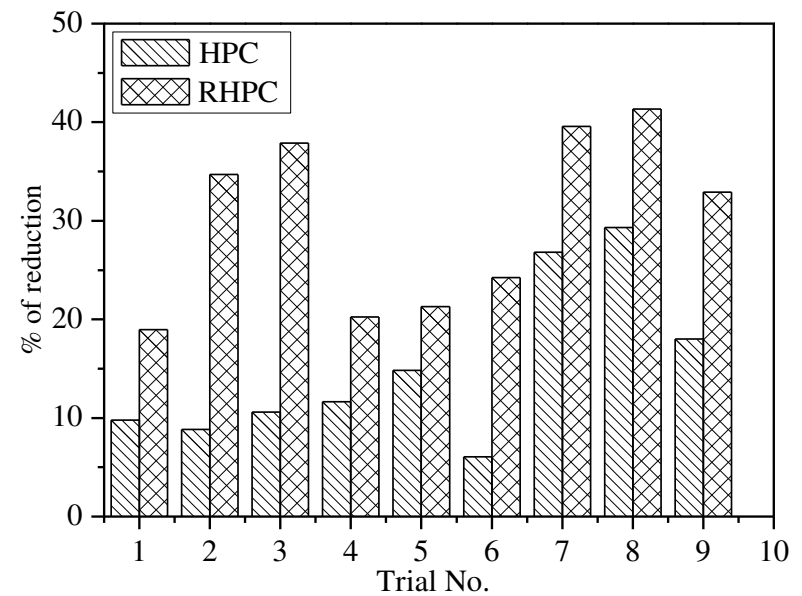

Fig. 13 Percentage reduction of average surface roughness under HPC and RHPC over dry milling of Ti-6Al-4V based on experimental runs.

As illustrated in Fig. 13, when cutting velocity is reduced to $16 \mathrm{~m} / \mathrm{min}$ and table feed rates are varied to 22,44 , and $68 \mathrm{~mm} / \mathrm{min}$, average surface roughness is reduced by 10.15 percent, 9.72 percent, and 17.44 percent, respectively, when Rotary HPC is used instead of conventional HPC. This reduction rate was shown to be greater ( 30.7 percent, 19.35 percent, and 18.18 percent) at the highest cutting velocity $(32 \mathrm{~m} / \mathrm{min})$ when the table feed rate was varied. As previously stated, increased cutting velocity benefits surface roughness reduction; additionally, the administration of coolant at high pressure via a rotating liquid applicator guarantees effective lubrication at frictional surfaces by rapid penetration into the cutting area. Properly directed high-pressured cutting fluids improve the tribological properties of the work material [39], and thus the fluid jets from the rotary applicator through the embedded nozzles improve the surface quality by improving the work material's tribological characteristics and effectively removing unwanted chips from the machined surface. This synergistic action results in an improvement in surface roughness.

\subsection{Progression of tool wear}

The tool's longevity during machining is determined by its wear resistance, toughness, and intense hardness to the work metal since the tool's life is continuously reduced by wear development. Thus, tool life can be defined as the effective length of cutting time required to achieve the specified surface 
quality. Tool wear is significantly influenced by the cutting temperature, vibration magnitude, and nature of tool-work interactions, as well as the machining circumstances. On the other hand, the pattern and geometry of tool wear have a substantial effect on the finished surface finish of the machined object [27].

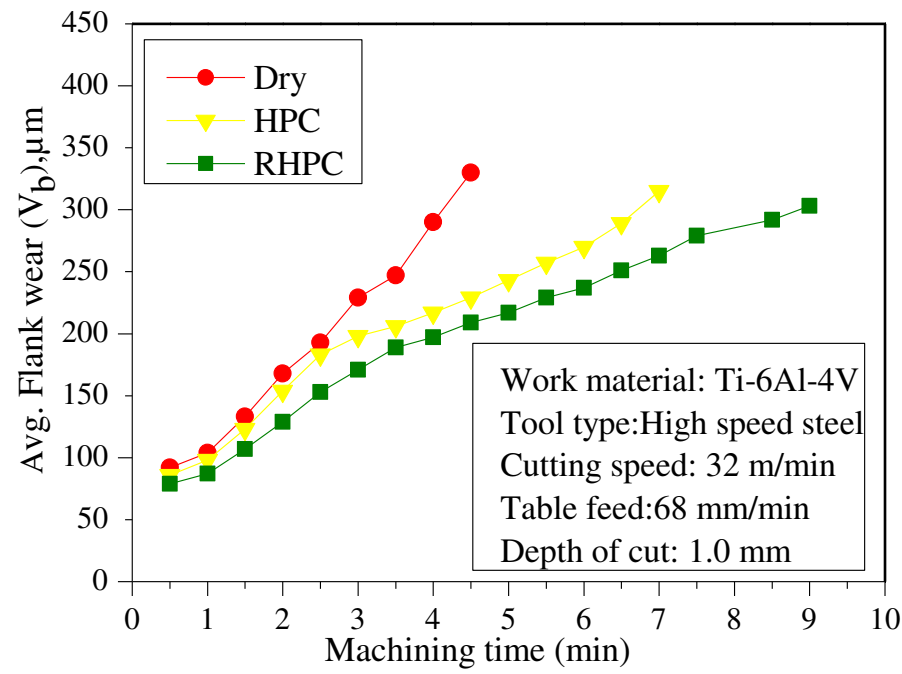

Fig. 14 Growth of average flank wear $\left(\mathrm{V}_{\mathrm{b}}\right)$ with machining time under different cutting conditions.

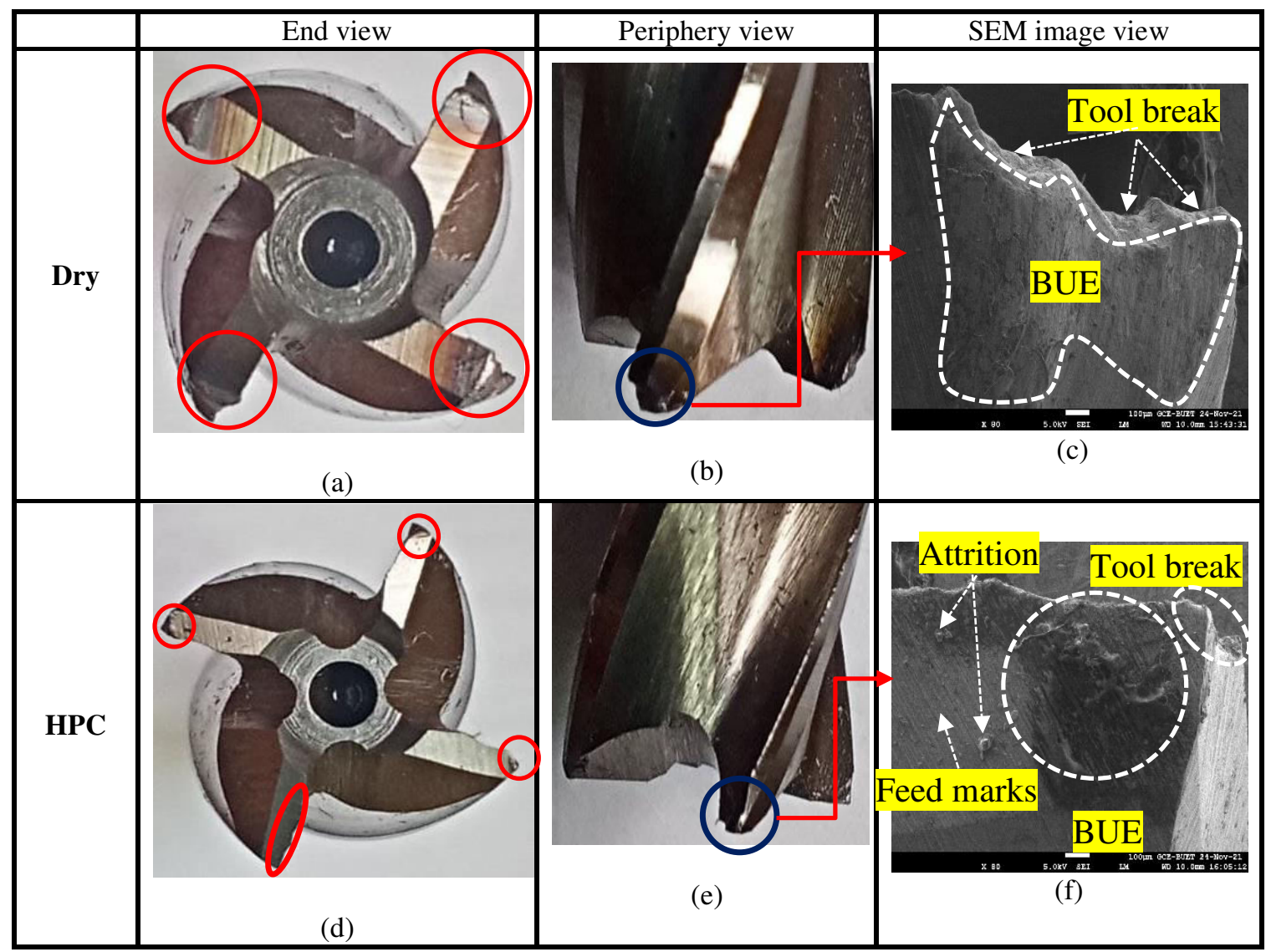




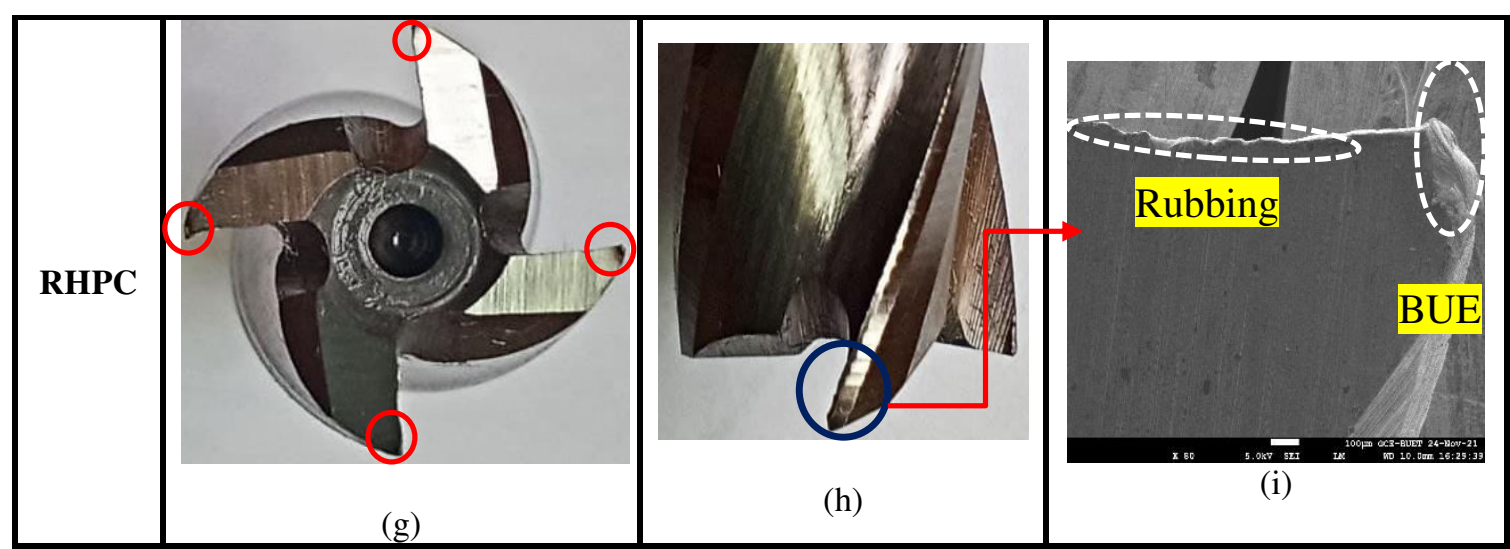

Fig. 15 Photographic view and SEM image of tool wear under different cutting conditions (red circles indicate the zone of flank wear).

Generally, the average flank wear $\left(\mathrm{V}_{\mathrm{b}}\right)$ is utilized to quantify tool life. The tool rejection criteria were fixed (average flank wear $300 \mu \mathrm{m}$ ), and ISO 8688-2 [40] was followed. As illustrated in Fig. 14, the quick growth of flank wear combined with increased nose wears significantly lowers tool life during dry milling. The level of flank wear was gradually reduced as the process progressed from dry milling to HPC and RHPC. Due to the high cutting temperature encountered during dry milling, considerable tool wear was noted. Due to the lack of cutting fluid, a tremendous amount of heat is retained at the cutting zone, which burns out the cutting edges and results in catastrophic failure (as shown in Fig. 15). Additionally, due to the reduced thermal conductivity of Ti-6Al-4V alloy, the majority of heat is absorbed by the tool, accelerating tool wear. On the other hand, both traditional HPC and RHPC have virtually eliminated burnout. Although the growth pattern of flank wear is comparable in HPC and RHPC, the rate of flank wear is faster in HPC due to BUE production and chipping, which is a side effect of insufficient cutting fluid penetration [33]. Reduced tool wear in milling under RHPC is allegedly the consequence of the synergistic impact of superior temperature management and friction reduction via the effective wedge effect of high-pressurized coolant jets. Additionally, in RHPC, correct impingement of coolant jets through the flute length enables a greater reduction in tool wear by producing a more effective oil lubricating layer around the cutting edges. This lubricating layer considerably minimizes rubbing and friction between tool/work contacts. Tool life was extended to 4.5 minutes for dry milling using the tool rejection criteria, which is increased to 7 minutes and 9 minutes for traditional HPC and RHPC, respectively. Finally, it can be inferred that RHPC can increase tool life by nearly $50 \%$ and $22.2 \%$ in milling Ti-6Al-4V alloy over dry and HPC, respectively, due to its superior cooling and lubrication. Additionally, Fig. 15 shows SEM images of worn end mill tools used in dry, HPC, and RHPC aided milling of Ti-6Al-4V alloy. The most common types of tool wear include built-up edge (BUE), rubbing, feed marks, attrition, and premature tool break, all of which are shown by white-colored dots forms. BUE development was seen to be greatest when end mills were used in dry cutting, owing to increased metal adhesion on the flank face, which degrades the surface quality of the machined product. The dramatic reduction in BUE formation in RHPC is believed to be the result of the correct impingement of high-pressured coolant jets. It is obvious that the tool edge breaks after a given amount of time of machining in both dry and HPCassisted milling, but not in RHPC. Furthermore, fewer feed marks were found in RHPC, indicating that the lubricating effect of RHPC was effective.

\section{Conclusions}

To further understand the advantages of milling Ti-6Al-4V alloy with elevated pressurized coolant jets, this study used a newly developed external rotary liquid applicator. Experiments have yielded some important findings, which are outlined here.

i. The forced convective heat transfer caused by the spinning fluid generated by our rotary applicator considerably boosts the cooling effect compared to conventional HPC.

ii. When milling Ti-6Al-4V alloy under RHPC, a considerable reduction in cutting temperature (7 25\% and 2 14\%, respectively) over dry and conventional HPC was achieved, which is a result of the increased convective heat transfer caused by proper cooling of the heat-affected zones.

iii. RHPC enables significant cutting force reduction at faster speeds and lower feed rates by reducing friction between tool-work surfaces, limiting BUE production due to chipping, and boosting cooling.

iv. At the maximum cutting velocity $(32 \mathrm{~m} / \mathrm{min})$ and the lowest table feed $(22 \mathrm{~mm} / \mathrm{min})$, the RHPC cutting condition produced the lowest average surface roughness $(0.82 \mathrm{~m})$. The primary 
explanation is believed to be the creation of a superior oil lubricating film under RHPC with less BUE and less vibration under the given cutting conditions.

v. In comparison to milling under dry and HPC conditions, RHPC delivered the longest tool life (9 minutes) with the least flank wear. Four circular high-pressured coolant jets successfully penetrate both tool-chip and tool-work interfaces in RHPC by breaking down the barriers of chips via a stronger wedge effect, which is believed to be the primary reason for these improved outcomes.

To summarize, the external rotary applicator designed to feed the high-pressure coolant jets is preferable to conventional cooling for boosting machinability greatly without changing cutting tool design. For milling such a superalloy, further studies could investigate the various micro and macro features of chips, tool wear, and residual stress in brief.

\section{Declarations}

\section{Funding}

The authors like to express their appreciation to the Ministry of National Science and Technology (NST), Dhaka, Bangladesh, Code No. 120005100-382117, GO No. 39.00.0000.012.002.05.20-04, Dated: 10/1/2021, for financially supporting this research. The authors would also like to acknowledge the Directorate of Advisory Extension and Research Services (DAERS) at BUET and the Department of Industrial and Production Engineering at BUET in Dhaka, Bangladesh for allowing them to conduct the research using their laboratory facilities.

\section{Competing interests}

The authors declare no competing interests.

\section{Availability of data and material (data transparency)}

All the relevant data are provided in the manuscript.

\section{Code availability (software application or custom code)}

Not applicable.

\section{Ethics approval}

The authors declare that this manuscript was not concurrently submitted to more than one journal. Additionally, the submitted material was unique and had not been previously published in any form or language.

\section{Consent to participate/consent for publication}

The authors declare that they participated in this paper willingly and that they consent to its publication.

\section{Authors contributions}

Mst.Nazma Sultana: conceptualization; writing original draft and methodology; data collection and formal analysis;

Nikhil Ranjan Dhar: supervision; Funding collection; project administration.

\section{Affiliations}


"Mst.Nazma Sultana", PhD student, Department of Industrial and Production Engineering, Bangladesh University of Engineerng \& Technology, Dhaka-1000, Bngladesh.

"Nikhil Ranjan Dhar", Professor, Department of Industrial and Production Engineering, Bangladesh University of Engineerng \& Technology, Dhaka-1000, Bngladesh.

\section{Corresponding author}

Correspondence to: Mst.Nazma Sultana.

\section{References:}

[1] Mia M, Khan MA, Dhar NR (2017a) Study of surface roughness and cutting forces using ANN, RSM, and ANOVA in turning of Ti-6Al-4V under cryogenic jets applied at flank and rake faces of coated WC tool. Int J Adv Manuf Technol, 93(1): 975-991.

[2] Khan MA, Mia M, Dhar NR (2017) High-pressure coolant on flank and rake surfaces of tool in turning of Ti-6Al-4V: investigations on forces, temperature, and chips. Int $\mathrm{J}$ Adv Manuf Technol, 90(5-8):1977-1991.

[3] Sultana MN, Zaman PB, Dhar NR (2019) A Review on different cooling/lubrication techniques in metal cutting. Am J Mech Appl, 7(4): 71-87.

[4] Zaman PB, Sultana MN, Dhar NR (2021) Multi-variant hybrid techniques coupled with Taguchi in multi-response parameter optimisation for better machinability of turning alloy steel. Adv Mater Process Technol, 1-21.

[5] Sultana MN, Zaman PB, Dhar NR (2020) Effects of Nano-fluids Assisted MQL in Machining Processes: A Review. Int Conf Mech Ind Energy Eng, 19-21 December, 2020, Khulna, BANGLADESH.

[6] Mia M, \& Dhar NR (2018) Effects of duplex jets high-pressure coolant on machining temperature and machinability of Ti-6Al-4V superalloy. J Mater Process Technol, 252: 688-696.

[7] Nandy AK, Gowrishankar MC, Paul S (2009) Some studies on high-pressure cooling in turning of Ti-6Al-4V. Int J Mach Tools Manuf, 49(2): 182-198.

[8] Ezugwu EO, Bonney J, da Silva RB, Machado A.R, Ugwoha E (2009) High productivity rough turning of Ti-6Al-4V alloy, with flood and high-pressure cooling. Tri trans, 2009, 52(3), 395-400.

[9] Ezugwu EO, Bonney J, Da Silva, RB, Çakir O (2007) Surface integrity of finished turned Ti-6Al$4 \mathrm{~V}$ alloy with PCD tools using conventional and high-pressure coolant supplies. Int $\mathrm{J}$ Mach Tools Manuf, 47(6):884-891.

[10] da Silva RB, Machado ÁR, Ezugwu EO, Bonney J, Sales WF (2013) Tool life and wear mechanisms in high-speed machining of $\mathrm{Ti}-6 \mathrm{Al}-4 \mathrm{~V}$ alloy with $\mathrm{PCD}$ tools under various coolant pressures. J Mater Process Technol, 213(8): 1459-1464.

[11] Mia M, Khan MA, Dhar NR (2017b) High-pressure coolant on flank and rake surfaces of tool in turning of Ti-6Al-4V: investigations on surface roughness and tool wear. Int J Adv Manuf Technol, 90(5-8):1825-1834.

[12] Klocke F, Sangermann H, Krämer A, Lung D (2011) Influence of a high-pressure lubricoolant supply on thermo-mechanical tool load and tool wear behaviour in the turning of aerospace materials. Proc Ins Mech Eng, Part B: J Eng Manuf, 225(1): 52-61.

[13] Sanchez LEDA, Palma GL, Marinescu I, Modolo DL, Nalon LJ, Santos AE (2013) Effect of different methods of cutting fluid application on turning of a difficult-to-machine steel (SAE EV-8). Proc Ins Mech Eng, Part B: J Eng Manuf, 227(2):220-234.

[14] Peng R, Liu J, Chen M, Tong J, Zhao L (2021) Development of a pressurized internal cooling milling cutter and its machining performance assessment. Prec Eng, 72: 315-329.

[15] Islam AK, Mia M, Dhar NR (2017) Effects of internal cooling by cryogenic on the machinability of hardened steel. Int J Adv Manuf Technol, 90(1-4): 11-20. 
[16] Sun X, Bateman R, Cheng K, \& Ghani SC (2012) Design and analysis of an internally cooled smart cutting tool for dry cutting. Proc Ins Mech Eng, Part B: J Eng Manuf, 226(4): 585-591.

[17] Ferri C, Minton T, Ghani SBC, Cheng K (2014) Efficiency in contamination-free machining using microfluidic structures. CIRP J Manuf Sci Technol, 7(2): 97-105.

[18]Peng R, Huang X, Tang X, Chen R, Hu Y (2018) Performance of a pressurized internal-cooling slotted grinding wheel system. Int J Adv Manuf Technol, 94(5): 2239-2254.

[19] Oezkaya E, Beer N, Biermann D (2016) Experimental studies and CFD simulation of the internal cooling conditions when drilling Inconel 718. Int J Mach Tools Manuf, 108: 52-65.

[20]Zhang C, Zhang S, Yan X, Zhang Q (2016) Effects of internal cooling channel structures on cutting forces and tool life in side milling of H13 steel under cryogenic minimum quantity lubrication condition. Int J Adv Manuf Technol, 83(5-8): 975-984.

[21] Shu S, Zhang Y, He Y, Zhang H (2021) Design of a novel turning tool cooled by combining circulating internal cooling with spray cooling for green cutting. J Adv Mech Des Sys Manuf, 15(1):1-11.

[22] Montgomery DC (2008) Design and analysis of experiments. John Wiley \& Sons.

[23]Cui D, Zhang D, Wu B, Luo M (2017) An investigation of tool temperature in end milling considering the flank wear effect. Int J Mech Sci, 131: 613-624.

[24] Weigand B, Beer H (1992) Fluid flow and heat transfer in an axially rotating pipe subjected to external convection. Int $\mathrm{J}$ heat mass trans, 35(7):803-1809.

[25] Katti V, Prabhu SV (2008) Experimental study and theoretical analysis of local heat transfer distribution between smooth flat surface and impinging air jet from a circular straight pipe nozzle. Int $\mathrm{J}$ heat mass trans, 51(17-18): 4480-4495.

[26] Torii S, Yang WJA (1995) Numerical analysis on flow and heat transfer in the entrance region of an axially rotating pipe. Int J Rot Mach, 2(2): 123-129.

[27] Sultana MN, Zaman PB, Dhar NR (2021) Hybrid Taguchi-PCA-utility approach for simultaneous optimisation of multiple responses in turning alloy steel. Adv Mater Process Technol, 1-18.

[28] Jamil M, Khan AM, Hegab H, Gong L, Mia M, Gupta MK, He N (2019) Effects of hybrid $\mathrm{Al}_{2} \mathrm{O}_{3}$ CNT nanofluids and cryogenic cooling on machining of Ti-6Al-4V. Int J Adv Manuf Technol, 102(9-12): 3895-3909.

[29]Zaman PB; Sultana MN, Dhar, N. R (2020) Quantifying the effects of cooling condition, tool type and cutting parameters on machinability of turning AISI 4140 steel using full factorial DOE. J Prod Sys Manuf Sci, 1(2): 23-39.

[30] Ezugwu E, Bonney J (2005) Finish machining of nickel-base Inconel 718 alloy with coated carbide tool under conventional and high-pressure coolant supplies, Tri Trans, 48(1): 76-81

[31]Liu, Z. Q., Cai, X. J., Chen, M., \& An, Q. L. Investigation of cutting force and temperature of endmilling Ti-6Al-4V with different minimum quantity lubrication (MQL) parameters, Proceedings of the Institution of Mechanical Engineers, Part B: Journal of Engineering Manufacture, 2011, 225(8), 1273-1279.

[32] Koné, F.; Czarnota, C.; Haddag, B.; Nouari, M (2013) Modeling of velocity-dependent chip flow angle and experimental analysis when machining 304L austenitic stainless steel with groove coatedcarbide tools. J Mater Process Technol, 213(7), pp.1166-1178.

[33] Sultana MN, Dhar NR (2021) Hybrid GRA-PCA and modified weighted TOPSIS coupled with Taguchi for multi-response process parameter optimization in turning AISI 1040 steel. Arc Mech Eng,68(1): 23-49.

[34] Braham-Bouchnak T, Germain G, Morel A, Furet B (2015) Influence of high-pressure coolant assistance on the machinability of the titanium alloy Ti 5553. Mach Sci Technol, 2015, 19(1): 134151.

[35] Mia M, Dhar NR (2017c) Optimization of surface roughness and cutting temperature in highpressure coolant-assisted hard turning using Taguchi method. Int J Adv Manuf Technol, 88(1-4):739753.

[36]Dhar NR, Kamruzzaman M (2007) Cutting temperature, tool wear, surface roughness and dimensional deviation in turning AISI-4037 steel under cryogenic condition. Int $\mathrm{J}$ mach tools manuf, 47(5): 754-759.

[37] Kamruzzaman M, Dhar NR (2009) The influence of high-pressure coolant on temperature tool wear and surface finish in turning 17CrNiMo6 and 42CrMo4 steels. J Eng App Sci, 4(6): 93-103.

[38] Kaminski J, Alvelid B (2000) Temperature reduction in the cutting zone in water-jet assisted turning. J Mater ProcessTechnol, 106(1-3): 68-73.

[39] Courbon C, Sajn V, Kramar D, Rech J, Kosel F, Kopac J (2011) Investigation of machining performance in high pressure jet assisted turning of Inconel 718: A numerical model. J Mater Process Technol, 211(11): 1834-1851. 
[40] Jebaraj M, Pradeep Kumar M, Yuvaraj N, Mujibar Rahman G (2019) Experimental study of the influence of the process parameters in the milling of Al6082-T6 alloy. Mater Manuf Procs, 34(12): 1411-1427. 